PROCEEDINGS OF THE WORLD CONFERENCE ON OZONE THERAPY IN MEDICINE, DENTISTRY AND VETERINARY. ANCONA (ITALY). SEPTEMBER 22nd - 23rd - 24th, 2017

\title{
Systemic ozone applications, Major autohemotherapy and Rectal Insufflation, evaluated according to the International classification of Evidence-Based Medicine. A new basis for reimbursement of medical expenses by private and social insurances [abstract]
}

\author{
Renate Viebahn-Hänsler ${ }^{1}$, Olga Sonia León Fernández², Ziad Fahmy ${ }^{1}$ \\ Medical Society for the Use of Ozone in Prevention and Therapy. ${ }^{1}$ Germany, ${ }^{2}$ Cuba
}

ABSTRACT

\section{ठ OPEN ACCESS}

\section{Citation}

Viebahn-Hänsler R, León-Fernández OS, Fahmy Z. Systemic ozone applications, Major autohemotherapy and Rectal Insufflation, evaluated according to the International classification of Evidence-Based Medicine. A new basis for reimbursement of medical expenses by private and social insurances [abstract]. Proceedings of The World Conference on Ozone Therapy in Medicine, Dentistry and Veterinary. Ancona (Italy). September 22nd - 23rd - 24th , 2017. J Ozone Ther. 2019;3(4):78. doi: 10.7203/ jo3t.3.4.2019.15550

\section{Academic Editor \\ Jose Baeza-Noci, \\ School of Medicine, Valencia University, SPAIN}

\section{Editor}

World Federation of Ozone Therapy, Bolgna, ITALY

\section{Received}

June 17, 2019

\section{Accepted}

December 08, 2019

Published

December 30, 2019

Intellectual Property

Renate Viebahn-Hänsler.

This is an open access article distributed under the terms of the

Creative Commons Attribution License (CC BY 4.0), which permits unrestricted use, distribution, and reproduction in any medium, provided the original author and source are credited.

Author Information

renateviebahn@t-online.de
Now that indications are clearly defined, applications have mostly become standardized and the active mechanisms have been well confirmed, medical ozone application in the form of the low-dose concept, is established and proven as a complementary medical method in the treatment of chronic inflammations or diseases associated with chronic inflammatory conditions.

More than 11,000 systemic ozone treatments in the form of Major Ozone Autohemotherapy (MAH) in 577 patients and ? 47,000 Rectal Insufflations $(\mathrm{RI})$ in 716 patients in various clinical studies are subjected to critical clinical assessment and classification according to the criteria of evidence-based medicine (EBM).

Statistically significant clinical and/or pharmacological improvements without side-effects or adverse reactions are found in all studies; special attention is drawn to maintaining hygiene when working with blood and to the use of ozone-resistent and biocompatible materials.

On summarizing the evidence classification under RCT + CT (Randomized Controlled Trials + Controlled Trials), i.e. Levels lb and Ila, 12 studies with 657 ozone-treated patients are obtained for MAH and 6 studies with 227 patients for RI.

As a result of the evidence here assessed, the two systemic ozone applications, $\mathrm{MAH}$ and $\mathrm{RI}$ are part of evidence-based medicine. Both applications are effective, safe and economic. 